\title{
Elementos simbolistas num poema de Raimundo Correia
}

Thiago César Viana Lopes Saltarelli I UFMG

\begin{abstract}
Resumo: Este artigo procura identificar traços impressionistas e simbolistas na poesia de Raimundo Correia, mostrando que, embora tradicionalmente considerado parnasiano, o poeta não se prende às características desse estilo. Para isso, faremos uma exaustiva análise dos aspectos formais $e$ semânticos de seu poema "Plenilúnio", para depois o inserir no contexto maior das séries literária e artística do final do século XIX. Palavras-chave: Raimundo Correia, Impressionismo, Simbolismo.
\end{abstract}

\begin{abstract}
A literatura brasileira do século XIX, apesar de ser tradicionalmente dividida em pelo menos quatro ou cinco estilos muito bem delimitados Romantismo, Realismo/Naturalismo, Parnasianismo e Simbolismo - apresenta, na verdade, um panorama bem mais complexo. Existe aí um intenso contato e diálogo entre os escritores, que se tornam leitores uns dos outros e se influenciam mutuamente. Isso se torna mais forte no final do século, quando, segundo Antonio Candido, a nossa literatura acabara de se constituir como sistema. O Realismo/ Naturalismo, o Parnasianismo e o Simbolismo, embora possuam marcos iniciais distintos, permanecem convivendo até a Semana de Arte Moderna. Além disso, escritores cuja obra traz características de mais de um estilo costumam ter sua trajetória literária dividida, didaticamente, em fases, numa tentativa de
\end{abstract}


enquadramento dessas características em categorias estilísticas predeterminadas. O importante, então, é constatar que na prática tais fronteiras não são assim tão bem delimitadas. Dentro desse quadro, pode-se perceber facilmente que a poesia de Raimundo Correia apresenta elementos considerados tipicamente impressionistas e simbolistas. Um ótimo exemplo para ilustrar essa afirmação é o poema "Plenilúnio", o qual transcrevemos e analisamos a seguir, procurando identificar os traços mais marcantes das duas estéticas mencionadas anteriormente.

\section{PLENILÚNIO}

Além nos ares, tremulamente, Que visão branca das nuvens sai! Luz entre as franças, fria e silente; Assim nos ares, tremulamente, Balão aceso subindo vai...

Há tantos olhos nela arroubados, No magnetismo do seu fulgor! Lua dos tristes e enamorados, Golfão de cismas fascinador!

Astro dos loucos, sol da demência, Vaga, noctâmbula aparição!

Quantos, bebendo-te a refulgência, Quantos por isso, sol de demência, Lua dos loucos, loucos estão!

Quantos à noite, de alva sereia O falaz canto na febre a ouvir, No argênteo fluxo da lua cheia, Alucinados se deixam ir...

Também outrora, num mar de lua, Voguei na esteira de um louco ideal; Exposta aos euros a fronte nua, Dei-me ao relento, num mar de lua, Banhos de lua que fazem mal.

Ah! quantas vezes, absorto nela, Por horas mortas postar-me vim Cogitabundo, triste, à janela, Tardas vigílias passando assim!
E assim, fitando-a noites inteiras, Seu disco argênteo n'alma imprimi; Olhos pisados, fundas olheiras, Passei fitando-a noites inteiras, Fitei-a tanto, que enlouqueci! Tantos serenos tão doentios, Friagens tantas padeci eu; Chuva de raios de prata frios A fronte em brasa me arrefeceu!

Lunárias flores, ao feral lume, - Caçoilas de ópio, de embriaguez Evaporavam letal perfume... E os lençóis d'água, do feral lume Se amortalhavam na lividez...

Fúlgida névoa vem-me ofuscante De um pesadelo de luz encher, E a tudo em roda, desde esse instante, Da cor da lua começo a ver.

E erguem por vias enluaradas Minhas sandálias chispas a flux... Há pó de estrelas pelas estradas... E por estradas enluaradas Eu sigo às tontas, cego de luz...

Um luar amplo me inunda, e eu ando Em visionária luz a nadar, Por toda a parte, louco arrastando O largo manto do meu luar... 
Esse poema de Raimundo Correia esboça uma imagem impressionista da lua, anunciada já em seu próprio título. Plenilúnio significa exatamente a lua cheia, que, na primeira estrofe, surge por entre as nuvens, tremulamente, sem contornos definidos. Seguem-se algumas descrições vagas e subjetivas, servindose o poeta de epítetos metafóricos, como "balão aceso", "golfão de cismas" e "sol da demência”. À medida que avançamos na leitura do poema, vemos o poeta se expor a essa lua, a essa luz fria e, a princípio, silente, que aos poucos começa a enlouquecê-lo. A aproximação entre o poeta e a lua se dá num crescendo contínuo, em direção ao final do poema, quando ambos estarão totalmente fundidos. Essas informações, por ora, já nos são suficientes para darmos início à análise do poema propriamente dita, em que desmembraremos suas partes para que se observem mais atentamente seus aspectos formais e semânticos.

II

"Plenilúnio" pode ser dividido em duas partes. A primeira abarca as quatro estrofes iniciais, em que o poeta, como já dissemos, esboça uma paisagem impressionista em que a lua é o tema principal. A preocupação aqui é realmente a pintura de um quadro, a descrição de uma cena, tanto que a voz pessoal é minimizada. Há uma predominância da terceira pessoa e, o que é mais interessante, a maioria dos versos constitui-se de frases nominais, como podemos perceber em "Lua dos tristes e enamorados, /Golfão de cismas fascinador!//Astro dos loucos, sol da demência, /Vaga, noctâmbula aparição!". Em todo esse trecho não foi empregado um só verbo. Quando estes ocorrem, encontram-se quase todos como verbos de ligação ou nas formas nominais - gerúndio, particípio e infinitivo. Assim, a ação é praticamente excluída dessas estrofes, que se apresentam como um grande painel estático e descritivo, embora a descrição não se faça objetiva e clara como era costume na estética parnasiana.

A segunda parte, por sua vez, inicia-se na quinta estrofe e vai até a décima segunda. Aqui, por oposição à primeira parte, a voz do poeta insere-se na composição, e tem-se um deslocamento de foco do objeto para o sujeito. Agora todas as frases são verbais, constituindo-se essas orações de verbos de ação, que imprimem maior movimento ao poema. Essa nova dinâmica, unida à subjetividade, 
acompanha o progressivo enlouquecimento do poeta, que se deixa embriagar pelos raios e pela luz do luar. As palavras pertencentes ao campo semântico da loucura são bastante recorrentes: só a palavra "louco" aparece cinco vezes, ainda reforçada pelo verbo "enlouqueci" - que não por acaso está na primeira pessoa. Há também "alucinados" e "doentios". Essa última, se não remete especificamente a um estado de loucura, faz uma ponte para outras palavras que sugerem ao menos um estado de perda de consciência ou de racionalidade, como "febre", "embriaguez" e "ópio".

Nesse sentido, é muito interessante observarmos a metáfora do décimo verso, sol da demência. O poeta caracteriza a lua pelo negativo do seu oposto. Expliquemos melhor: tradicionalmente, desde culturas muito antigas, o sol e a lua se opõem, pois cada um preside momentos opostos do dia - a manhã e a noite, respectivamente - em que se realizam atividades diferentes. O poeta, ao dizer que a lua é um sol, denominou-a pelo seu oposto, que na nossa cultura sempre foi associado a calor, luz vital, iluminação e, a partir do sentido figurado dessa última palavra, a racionalidade, equilíbrio e harmonia. Entretanto, a metáfora não pára aí, sendo esse sol que caracteriza a lua um sol da demência, ou seja, um negativo do sol tradicional. Sendo demente, ele não poderia se associar à racionalidade e ao calor, ligando-se portanto à luz fúnebre, ao frio e à loucura. $O$ importante dessa metáfora é que ela não apenas sugere um estado de ebriedade, mas põe esse estado em contraste com a racionalidade e a consciência, promovendo uma inversão de valores tradicionais de concepções clássicas de mundo.

\section{III}

O estado de embriaguez e de perda de consciência de que falamos é refletido pela estrutura aparente do poema. O ritmo é criado por versos eneassílabos, em sua maioria com acento na quarta e na nona sílabas. Podemos ainda dividir cada verso em dois hemistíquios de quatro sílabas, sendo cada um semelhante a uma frase musical. Cada verso possui, portanto, duas frases musicais. Aqui é necessário escandir o primeiro hemistíquio de forma análoga à escansão do próprio verso. A quinta sílaba de cada verso, portanto, pertence ainda ao primeiro hemistíquio, funcionando como a última sílaba átona de um verso, que não é contada na escansão. Assim, retornando à analogia com a organização do discurso na música, a quinta sílaba de cada verso pertence à sua primeira frase musical, 
como se fosse um tempo fraco e por isso menos acentuado que o anterior, que é a quarta sílaba do verso e última sílaba do hemistíquio. ${ }^{1}$ Tomemos como exemplo o primeiro verso:

$1^{\circ}$ hemistíquio

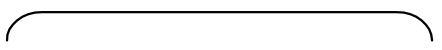

$1^{\text {a }}$ frase musical

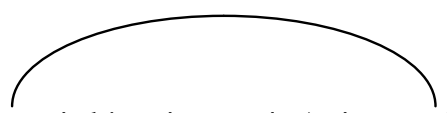

a | lém | nos | A | res, || tre | mu | la | MEN | te,

nível do verso:

nível do hemistíquio:

nível da frase musical:

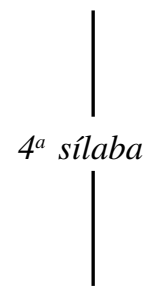

última sílaba

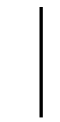

forte fraco $2^{\circ}$ hemistíquio

$2^{\mathrm{a}}$ frase musical

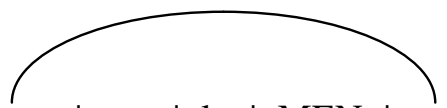

última sílaba

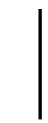

forte fraco

Essa constância do ritmo, unida ao caráter embalador das frases musicais, torna a leitura do poema bastante envolvente, inebriante, além de sugerir um movimento circular, sem grandes variações, que leva o poeta à tontura e casa bem com a imagem da roda presente no quadragésimo quarto verso. Todas as imagens adquirem a cor da lua e passam a ser vistas em roda, num giro inebriante que assimila o formato do astro e é acompanhado pelo ritmo.

1. Essa análise pode ser facilitada pelo sistema de escansão dos versos conhecido como contagem espanhola, utilizado na poesia espanhola e italiana, o qual segue o padrão grave para finais de versos. Assim, são contadas as sílabas posteriores à última tônica de cada verso. Nesse caso, o poema "Plenilúnio" seria estruturado em versos decassílabos, os quais poderíamos dividir em dois hemistíquios de cinco sílabas. Logo, a quinta sílaba do verso, análoga à décima, não ficaria "sobrando" no primeiro hemistíquio, de quatro sílabas poéticas segundo a contagem francesa. Para mais informações sobre os sistemas de escansão, conferir CHOCIAY, 1974. 
Aumentando ainda mais a sensação de movimento circular e de vertigem, há uma repetição excessiva de palavras e expressões. Nas estrofes de cinco versos, o quarto é sempre uma retomada do primeiro com algumas poucas alterações. Relembrando que esse ritmo se presta a trazer a idéia de loucura e de perda de consciência para o plano da expressão, um outro elemento a ser considerado é a pontuação do texto. Dos cinqüenta e quatro versos, oito terminam em exclamação e outros oito em reticências. Isso reflete, respectivamente, as grandes oscilações emocionais promovidas por um estado de loucura e embriaguez e a falta de conclusão de um raciocínio objetivo. Sobretudo as reticências mantêm o caráter vago das imagens do poema.

Uma vez que estamos analisando o seu estrato fônico, gostaria de ressaltar ainda o surpreendente jogo sonoro do quadragésimo oitavo verso:

aliteração de p: $\quad$ Há (P)ó de estrelas (P)elas estradas...

aliteração de tr: $\quad$ Há pó de es(TR)elas pelas es(TR)adas...

eco do grupo elas: $\quad$ Há pó de estr(ELAS) p(ELAS) estradas...

O verso diz que pelas estradas há pó de estrelas. Ora, para que estas tenham sido transformadas em pó deve ter sido necessária uma pulverização, que é sugerida pela dureza dos sons oclusivos e vibrantes de $p, t$ e $r$. O pó que restou das estrelas naturalmente emite fagulhas que cintilam pela estrada, e esse brilho pode ser sugerido pelo eco, como se algo ficasse piscando intermitentemente.

\section{IV}

Passemos agora ao exame das principais figuras de linguagem empregadas pelo autor. A primeira é a metáfora, utilizada sobretudo para caracterizar a lua cheia. Já comentamos uma delas, que compara a lua a um sol de demência. Na primeira estrofe há outra, que caracteriza a lua como um balão aceso que sobe e se desvela por detrás das nuvens. Essa metáfora ainda pertence ao domínio aéreo e mantém a lua no céu. Mais à frente comentaremos esse movimento de subida do balão. Já na segunda estrofe, há uma sofisticação das metáforas, que passam para o domínio da água e prosseguirão assim até o final do poema. Temos, portanto, a lua caracterizada como golfão, como mar, como lençóis 
d'água, e seus raios caracterizados como chuva. Há também os verbos "nadar" e "vogar", esse último significando navegar, deslizar suavemente por uma superfície aquática. Desse modo, a figuração da lua cheia a partir de metáforas aquáticas aumenta a fluidez do poema e o caráter fugidio das imagens, que já se anunciava com o balão que subia e com as nuvens.

A outra figura largamente utilizada pelo autor é a sinestesia. A embriaguez promovida pelos banhos de lua que o poeta se dá mobiliza todos os seus sentidos e faz com que eles misturem as sensações percebidas pelo sujeito. À visão, que seria o primeiro sentido mobilizado pelo ato de contemplar a lua, une-se o paladar na terceira estrofe, em que alguns indivíduos bebem a refulgência do luar. Na estrofe seguinte há uma mistura da visão com a audição: os alucinados que se deixam ir no fluxo da lua ouvem cantos de sereia. Aqui há que se ressaltar a carga semântica da palavra "sereia", que remete à sedução e à conseqüente perda da razão por parte do seduzido. A quinta e a oitava estrofes ficam por conta de mobilizar o tato. A sensação presente é sobretudo de frio, oriunda dos banhos de luar e da chuva de raios de prata que o poeta afirma ter tomado. Finalmente, na nona estrofe, há uma participação do olfato nas sensações provocadas pelo plenilúnio. Este se torna uma caçoila - vaso onde se queimam resinas e plantas aromáticas - e evapora um perfume letal.

\section{$\mathrm{V}$}

Analisados os principais aspectos formais e semânticos do poema, e sabendo-se que seu autor é considerado um parnasiano, faz-se necessário inseri-lo num contexto maior, ou antes, confrontá-lo com a série literária e as características predominantes de cada estilo. Retornando à divisão do poema proposta na segunda seção deste ensaio, observamos que a primeira parte é constituída de quatro estrofes, enquanto a segunda parte constitui-se de oito. Assim, a parte em que a voz do poeta ganha espaço é o dobro daquela em que há uma maior objetividade. Isso faz com que essa obra afaste-se da estética parnasiana, que prega uma focalização nos objetos e um apagamento da voz do sujeito no poema. Aliás, em "Plenilúnio", mesmo a primeira parte, em que o foco do poema está no objeto, afasta-se do Parnasianismo, pois não apresenta uma descrição detalhada e objetiva da lua. Como já dissemos, tem-se aí um esboço impressionista, em que as imagens são mais sugestivas que descritivas. As nuvens e a recorrência da água presentes no poema 
confirmam essa idéia, pois ambos são elementos caros aos impressionistas, inspirando diversos quadros de Monet e composições de Debussy.

Seguindo essa tendência, poderíamos dizer que esse poema de Raimundo Correia tem muitas afinidades com a estética simbolista, a começar pelo tema, pela escolha de um ambiente noturno e da lua que inebria e enlouquece o sujeito. Já se falou aqui sobre a oposição sol/lua e razão/loucura. Cruz e Sousa também fará um poema intitulado "Lua", em que esta será associada ao mesmo frio, à angústia e ao caráter fúnebre presentes em "Plenilúnio". O uso de reticências e a repetição de palavras também são recursos utilizados muito mais pelos simbolistas do que pelos parnasianos. Em relação às palavras, Raimundo Correia emprega inclusive algumas que são consideradas tipicamente simbolistas, como "noctâmbula", "amortalhar", "lividez" e "ópio". Essa última, associada na nona estrofe ao perfume que evapora, remete a uma característica capital da poesia simbolista que é a imagem do movimento de elevação, sugerindo a sublimação. Herança da poesia romântica, quando a fumaça dos charutos deformava a percepção objetiva das sensações e do mundo, esse movimento é associado na poesia simbolista justamente aos perfumes que evaporam, aos incensos que são queimados e sobem em direção ao céu. Em "Plenilúnio", além da imagem do perfume, há a imagem do balão que sobe, também esfumaçado pela presença das nuvens. Mais uma vez nos remeteremos a Cruz e Sousa, citando um trecho de seu poema "Siderações":

Para as Estrelas de cristais gelados

As ânsias e os desejos vão subindo,

Galgando azuis e siderais noivados

De nuvens brancas a amplidão vestindo...

[...]

Dos etéreos turíbulos de neve

Claro incenso aromal, límpido e leve,

Ondas nevoentas de Visões levanta...

Atentemos para a semelhança na construção do ambiente, nas imagens evocadas, nas palavras utilizadas pelos dois poetas.

Um último elemento que aproxima o poema de Raimundo Correia do Simbolismo é o ritmo. Os versos eneassílabos de acento na quarta e nona sílabas não são comuns nas estéticas clássicas. Eles caracterizam composições que

2. CRUZ E SOUSA, 1995. p. 64. 
tentam aproximar-se da música, sobretudo dos gêneros baladas, canções e árias independentes. Esses gêneros também são herança do Romantismo, podendo ser associados ao lied, posteriormente retomados pelos impressionistas, como Debussy, Ravel e Gabriel Fauré. Não é por acaso que esse ritmo foi utilizado por Alphonsus de Guimaraens na quinta seção do livro Dona Mística, que se intitula "Árias e canções", e por Manuel Bandeira, em sua "Baladilha arcaica".

\section{VI}

Para encerrar, proponho agora uma nova divisão para o poema. Na sétima estrofe o poeta afirma: "Seu disco argênteo n'alma imprimi". Ocorre aqui, portanto, uma fusão entre a lua cheia e o sujeito, ou pelo menos uma espécie de assimilação daquela por parte deste. Assim, há uma primeira parte do poema - da primeira à sexta estrofe - em que a lua é apresentada, depois a voz do poeta aparece e este se aproxima cada vez mais da lua, que se torna o seu ideal, como comprova o vigésimo verso. Na sétima estrofe, portanto, ocorre a fusão entre ambos. A lua encontra-se inscrita no peito do poeta. Essa fusão, essa assimilação não cessa aí, e continua a crescer na segunda parte, agravando o estado de ebriedade do poeta - surge o adjetivo "feral" e tudo adquire a cor da lua e passa a girar - até que na última estrofe a lua já não está presa à alma do poeta, mas envolve-o todo como um manto; já não se encontra inscrita em seu peito, mas circunscreve-o todo. Assim, retomamos a idéia inicial do movimento circular inebriante, expresso inclusive pelo ritmo. Essa leitura procurou demonstrar, portanto, que nesse poema a lua inebria o poeta e ativa todas as suas sensações, misturando-as todas, até envolvê-lo e confundir-se com ele. Demonstramos também como todas essas idéias são bem retratadas no plano da expressão. Ressaltamos, ainda, que muitas vezes um poema pode se afastar das características do estilo no qual seu autor é inserido pela crítica, aproximando-se muito mais de outras estéticas, por vezes servindo inclusive de inspiração para elas. 
Résumé: Cet article cherche à identifier des traits impressionnistes et symbolistes dans la poésie de Raimundo Correia. Bien quill soit consideré traditionnellement parnassien, ce poète ne s'attache pás aux caractéristiques de ce style. C'est pour cela que nous ferons une analyse épuisante des aspects formels et sémantiques de son poème "Plenilinio", pour le placer plus tard dans le contexte majeur des séries littéraire et artistique de la fin du siècle XIX.

Mots-clés: Raimundo Correia, Impressionnisme, Symbolisme.

\section{Referências Bibliográficas}

CANDIDO, Antonio. Formação da literatura brasileira. 9. ed. Belo Horizonte: Itatiaia, 2000. $2 \mathrm{~V}$.

CHOCIAY, Rogério. Teoria do verso. São Paulo: McGraw-Hill do Brasil, 1974.

CORREIA, Raimundo. Poesias completas. São Paulo: Ed. Nacional, 1948. 2 v.

CRUZ E SOUSA, João da. Obra completa. Rio de Janeiro: Nova Aguilar, 1995.

IVO, Ledo. Raimundo Correia: poesia. 2. ed. Rio de Janeiro: Agir, 1963. 